International Journal of Management Science and Business Administration

Volume 7, Issue 5, July 2021, Pages 43-51

DOI: $10.18775 /$ ijmsba.1849-5664-5419.2014.75.1004

URL: https://doi.org/10.18775/ijmsba.1849-5664-5419.2014.75.1004

\title{
A Study on Contribution of Digital Human Resource Management towards Organizational Performance
}

\author{
${ }^{1}$ Dr. A. Varadaraj, ${ }^{2}$ Dr. Belal Mahmoud Al Wadi \\ ${ }^{1}$ professor, Alliance School of Business Bengaluru, India \\ ${ }^{2}$ Assistant Professor- Learning and Development Consultant, LEVENBERT for Studies and Consulting - \\ Sultanate of Oman \\ avraj28@gmail.com; Belal.alwadi@yahoo.com
}

\begin{abstract}
Digital (HRM) Human Resource Management is digital upgrading in the field of Human Resource management. The working process of DHRM will take place through mobile, electronic media, social media through the internet, and also with the help of IT (information technology). All these resources will make HRM more significant in the present situation. Digital HRM is capable of doing Human work by the means of software, through several apps, and with the internet embedded in it. Digital Human Resource will assist organizations through the optimization of Social, Mobile, Analytics, and Cloud (SMAC) technology, towards management and responsibility in helping them to ensure that assumptions and expectations within the organization drive the right behavior. Digitalization in HRM will make it more efficient and relevant in the future. Without digital transformation, HRM will lag far behind the demands of the organization worldwide. This research paper tries to highlight the role of digital HRM in improving the performance of the organization. The data used for this research are secondary. The outcome of the research would be very important for a business organization to implement digital human resource management and also for improving and enhancing organizational performance.
\end{abstract}

Keywords: Organization, Business firm, Digitalization, Business strategy, Business enhancement.

\section{Introduction}

The rapid growth in technology has increased the digital performance of the organization, its impact on society, and the workflow of the organization. The digital revolution has an impact on organizations at all levels. Furthermore, it puts pressure on organizations and its employee to adapt to the rapidly changing world and the increase of digital technology. Digitalization has become a buzzword in the business world and is recognized as something organizations must embrace in order to stay relevant (Goldstein, 2015; Kontić \& Vidicki, 2018).

Nowadays, technology in computers has replaced all manual work (Cöster et al., 2019).Smart computer programs such as Artificial Intelligence (AI), also has replaced non-repetitive intellectual tasks that can access a bigger amount of information, commonly known as „Big data (Makridakis, 2017; Shah et al., 2017). The traceability also increases as more digital tools are connected to the internet, the „Internet of Thingse (Ebersold \& Glass, 2015). Digitalization pervades everything that can be digitized (Halid et al., 2020). not only changes how people communicate and interact as humans but in turn also transforms how organizations operate (Larkin, 2017).

Previous research focuses on digitalization for marketing and business performance such as customer preferences, buying behavior, and customer relationship management. However, how it affects the organization internally is less discussed in the field of academic research, especially about HRM. Therefore, the objective of this study is to investigate deeper into HRM in the digital age. More specifically, this study aims to gain a deeper understanding of the HRM digital research field and its relationship with organizational performance.

\section{Literature Review}


To know more about digital human resources one should first understand the exact meaning of it. (S`ušnjar et al., 2016) defined DHRM as a practice that is highly used for recruiting, selecting, socializing, training, and developing the career opportunity for the participants as well as for the organization to take the right employee to work in the organization. (Bredin \& Söderlund, 2011; KAVANAGH et al., 2009) explained DHRM as practices relating to the relationship between the employees and the organization in which they work. Also, HRM The development of information technology has played a key role in the evolution of DHRM.

(Maditheti, 2017) in this business world, all technologies are re-appearing in a new form in order to attract and gain more recruitment of employees in the organization. The main transformation took place in HRM from conventional HRM to a Digital HRM by implementing new policy and strategy to attract organization.

(Saini, 2018) described DHRM as maintaining all HRM work with the help of technology, through several applications and internet-connected to it.

(Iwu, 2016) conducted study at sub-Saharan African universities found that maximum percentage of employees agreed that E-HRM would increase their performance, also studied the impact of digitization on HR development, talent management, and performance at work. The findings of the research indicate that there is a positive impact of digital transformation on all variables.

(Tripathi \& Kushwaha, 2017) strongly recommended that organizations to bring forward digitization in the HRM practices as it has become very significant these days.

(Shah et al., 2017) shown that digitization of HRM processes enables to remove many routine tasks, to reduce the risk of human error, and empower experts to solve important issues, enabling them to use their knowledge and skills more effectively in solving business problems.

Therefore, based on previous research it shows that execution of digital HRM is important for an organization to improve their performance and maintain relevance in the digital era.

\subsection{HRM and Digital HRM}

In the present scenario, business is conducted with the needs and demands for the international business motive, also goods transfer takes place from one country to another, services, managerial knowledge, and technology transfer also takes place between countries. Globalization made the entire world small in the means of communicating with others. The financial and economical patterns of the world have been integrated with better advancement.

In today's digital world where digital human resource management plays a prominent function when compared to conventional human resource management due to the demand of the organization. Many organization needs highefficient Digital Human Resource Management for better organizational performance. The HR department must welcome digital transformation in HR and must also upgrade the policy of HR according to the need for digital transformation. Digital Human resources management faces many challenges and difficulties in order to give the best quality of work for the organization across the world. In order to achieve in the competitive market structure organization must expand the trading globally.

It is difficult for Human Resource Management to adapt themselves to a digital transformation and dealing with complexity while shifting the work process and its progress to a digital platform. Digital Human Resource in today's world plays an important role in the organization and other business operation by the means of creating momentum and internal capability.

(Maditheti, 2017) the main motive of the HR manager in present scenario is to adapt to the change in the business market structure and to implement the necessary change and enhance the performance in order to make successive plans for the organization. The efficiency of HRM will be seen through the recruitment process mainly.

In an Internet-based Society, it would be very helpful for the human Resource Management Department to try to understand and analyze the relationship between Human Resource and Information Technology. The analysis must be implemented in HR for enhancing the performance of HR along with the integration of Information technology. Adaption of digital technology will create a complete balance between efficiency and innovative aspect of any organization. Due to Human Resource management being a central unit for many organizations it is responsible for designing the organizational structure, the collaboration between the two is highly significant.

\section{Conceptual View on Digital Hrm}

\subsection{How Digital HRM Work?}




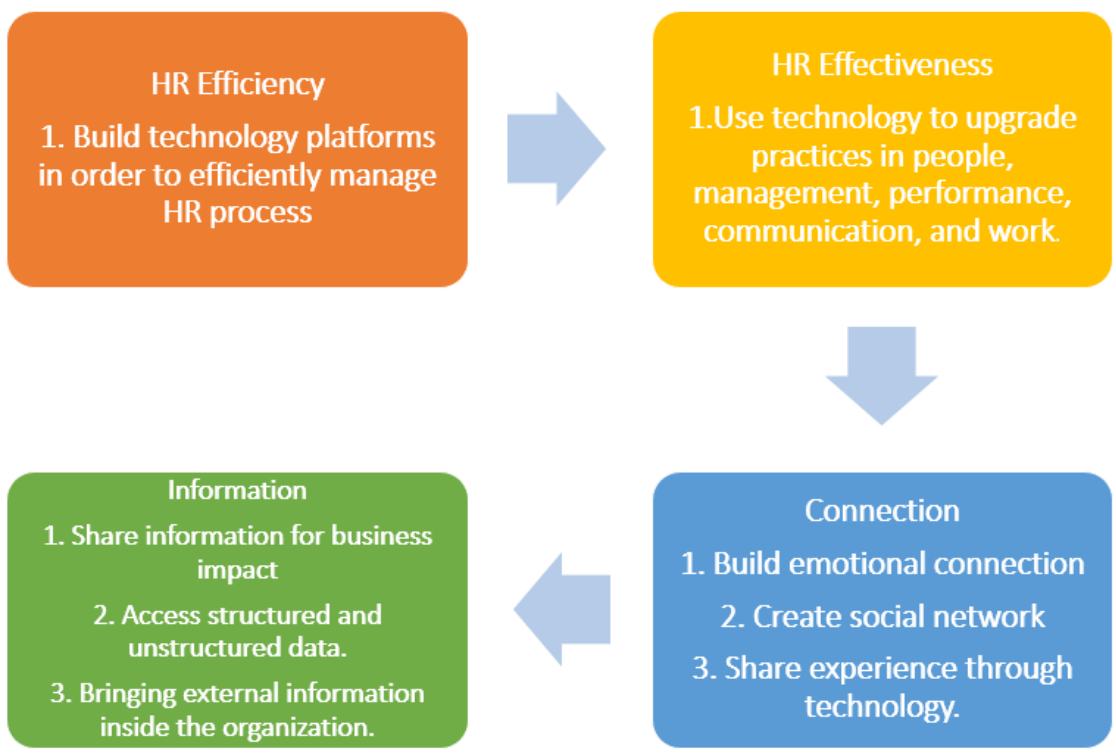

Figure 1: Digital HR agenda

(Halid et al., 2020) proposed a framework highlighting the 4th Industrial Revolution on how digital technology has completely changed the organization, society, operating structure of the organization, life style of employees, etc.

(Maditheti, 2017)Thus, in order to be relevant in this era, digitization is something that an organization has to bring in specifically in managing HR. For example, traditional methods of recruitment and selection cannot reach the wide geography of millions of people at once. However, technology has made recruiting more efficient and effective to distribute information more attractively. Unilever is the multinational consumer goods company accessing worldwide has now adapted a digital platform for hiring new employees. Now the company is fully experimenting with digital platforms like online games, social media, AI for the further recruitment process.

With the digital media, employees will know the complete structure involved in the training process and they can attend the training program for any location by attending the training class through an online platform. Digital Human Resource Management is very helpful in HR process and it also plays an important role for organizational development. Proposed a framework on how digital technology plays a significant role by enhancing the performance of the organization through the cloud-based network and helping in certain processes like analytics, talent management analysis, borderless teams, etc.

(Larkin, 2017) the digital transformation in Human Resource Management can be classified into 3 main groups as

1. Inward

2. Outward

3. Across

(Saini, 2018) Inward: if an organization is classified under inward it means that the organization is embedded with digital technology and the employees working in the organization communicate through digital means like mailing, video calls with mobile devices. The performance of the employees is carried out through digital means.

(Saini, 2018) Outward- if an organization is classified under outward it means that the management of the organization is trying to make the employees involved in digital means by using smartphones to perform their work. By performing 
their work through mobile phone an employee can be work from any place, anywhere, at any time. Through this, the involvement of the employees in their work will increase.

(Saini, 2018) if an organization is classified under across it means that the change in the organization is bigger. Digitalization in HR will help in bringing innovation, collaborations, and efficient strategy in the organization. Digitalization makes the organization to attain a global position because they share and gain knowledge from their collaborative global organization.

\subsection{Elements of Digital HRM}

In the present digital world Human resource Management have adapted technology to stand it the competitive digital world. Human Resource Management has to transform from conventional to digital form. The following elements are required to make a transformation in HRM.

\section{A. Digital workforce}

In the millennial era, current generations are considered the digital workforce, they have internet-connected devices and web-based applications and services have always fascinated their everyday lives. By having these employees, the organization needs to be digital in order to engage with a digital employee [27]. Therefore, digital HRM is embedded with mobile apps, design thinking, video, behavioral economics, and the use of system analytics [15].

\section{B. Digital work and task}

The work in organization has taken huge transformation utilizing a digital platform in works as well as in management. Every organization in this present scenario must make integrate digitalization in the work process which will help in reducing manual work. Organizations also need to use digital tools and media to connect and communicate with the employee. Work and task in organization also need to organize digitally.

\section{Digital support management}

This involves planning, implementing, and using digital technologies to support HRM activities such as payroll processing, reward and compensation, performance management, training, and development, etc.

\section{Updated HR technology}

(Saini, 2018) There is a significant change in conventional human resources and its changing pattern towards digital human resources through a cloud-based networking system. The human resource field has shifted from conventional operation to mobile device based operation. Social and mobile functionality is considered an important need for recruitment selection.

\subsection{Benefits of Digital Human Resource Management}

\section{Old Rules}

1. HR department focus on process design and harmonization to create standard HR practice.

2. HR selects a cloud-based vendor and implements out-of-the-box practices to create scale.

3. HR centre of excellence focus on process design and process excellence.

4. HR focuses on self-service as way to scale service and support.

5. HR programs are designed for scale and consistency around the world.

\section{New Rules}

1. HR department focus on optimizing employers productivity, teamwork, engagement, and career growth.

2. HR builds innovative, company-specific programs, and leverages the platform for scale.

3. HR centre focus on excellence leverage, Al, Chat, APPS, and other advanced technology.

4. HR focuses on enablement to help people to get work done in more effective way.

5. HR programs target employees segments, personae, and specific groups. 
Figure 2: Digital HR old vs new rules

Today's world has completely changed by the means of living style, work pattern, the organizational structure of the business, and the way how it is carried out. DHR will be impacting on every aspects of HRM. Initially DHRM helped the managers and employees of the organization to have a mindset changing to implementing technology, managing the organization digitally, all these will lead to a biggest change in the organization.

Highlights that digitalization changes the way employees communicate and interact in the workplace, what they expect from their employer and careers, where work location is and when work is conducted. Since, the evolution of digitalization impacts organizations at many levels, thus it needs development and adaption of new knowledge and new ways of working.

\section{Case Study on Digital Human Resource and its Practice in a Popular Business Firm}

Digitalization is a very significant topic which gained a lot of attention among the business firm, several entrepreneurs, organizations, and industries. This section will elaborate the use of Digital HR by several leading organizations across the world, its benefits, and the importance of Digital HR in the organization. These case studies highlights the organization using digital HR.

\subsection{Anchor Trust}

Anchor Group is one of the top leading Non-for-profit housing organization based in the United Kingdom. They wanted the recruitment process to be in a better way and to take the best candidate to work in the organization. Their main motive was to take more employees to work in the organization in the right manner. For the recruitment process, they utilized Chabot which was embedded in Facebook Messenger with several sets of questions which allows the management to engage with the candidate directly by sharing the screen of their device. They also created clear social media campaigns for guiding the participants in the recruitment process and by guiding them to use Chat bot. FB analysis helped the organization to find out which questions will be suitable for most of the target participants for recruitment. By developing and launching Chat bot, the recruitment process of Anchor Trust improved in all aspects.

The traditional recruitment process of Anchor trust was by making the participants apply on the organization website in which the conversation rate was just 2 percent but through Chat bot the conversation rate was about 25 percent. The cost gained by social media campaign for recruitment through the traditional method was 50 GBP but now it was about 18 times higher than before. And the number of the applicant for a month reached about 80 percent.

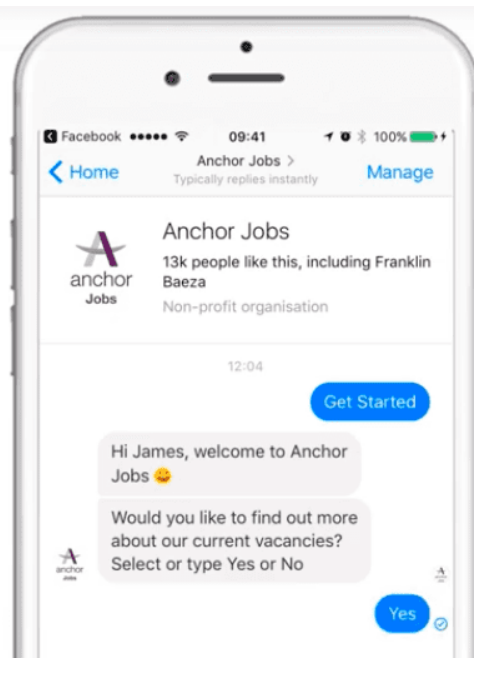

Figure 3: Chatbot created by Anchor trust for improving recruitment process 


\subsection{Deloitte- (Making Learning all Fun and Games)}

In January 2013 Harvard Business reviewed published an article pointing out Deloitte's - Made learning a game. This suits as a wonderful example of how gamification can improve a serving digital platform and its environment. Deloitte wants to improve the training programs known as the DLA (Deloitte Leadership Academy). It is considered as one of the difficult task site training is difficult to make the participants to completely understand it.

But in order to make the training program interesting, they implemented several gaming elements like designing, playing and competition in the real world in a form of a gaming world. Deloitte was able to interact with the users through embedding missions, video lectures, tests, and quizzes. The outcome of this training program revealed that nearly 38 percent of users come back to Deloitte Leadership Academy every week.

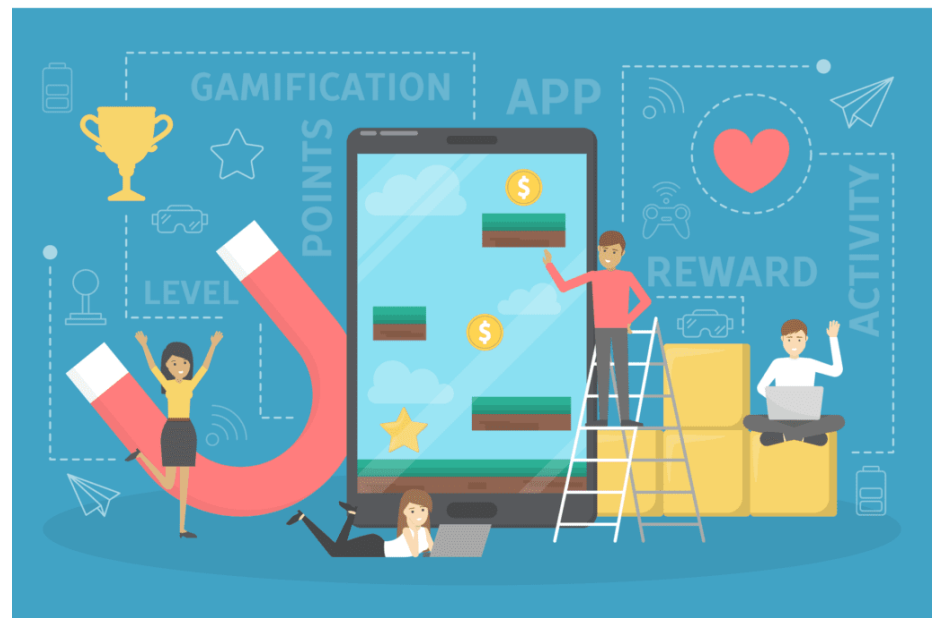

Figure 4: Gamification created by Deloitte for enhancing the existing digital process

\subsection{Walmart- (Automation as a Way to More Meaningful Work)}

Walmart is one of the leading retail corporations that always wanted to be innovative in all means. This organization always looks for an opportunity to be innovative and to seek the attention of not only customers but also employees. So Walmart has developed an automation process for the employees to contact the customers directly.

The outcome of this process was found in the fast-growing shopping area. They decreased the number of cashiers by making the customers experience self-checkout and trainer the workers utilizing to be the best personal shoppers. Walmart created a virtual platform for training and preparing workers for any situation to occur in the future. The shift in the working process has given a higher amount of satisfaction for the employees as well as the customers who are shopping.

\subsection{IBM}

IBM is one of the leading organizations with nearly 500,000 employees and they are creating a path for digital HR by experimenting new digital Human Resource Management. For managing the employees and their working process they developed Checkpoint using the FB which will help in increasing the engagement of workers, goal management, and alignment. IBM has shut the conventional Learning management and replaced it with a digital learning platform. With this digital platform, employees can easily publish their work which they consider important for themselves, and developing their work by learning or gaining knowledge through the internet. IBM has developed a career management system to empower the employees and also helps them to seek new jobs, to find new assignments by looking into peers' working patterns.

\subsection{RBC (Royal Bank of Canada)}

$\mathrm{RBC}$ is trying to re-invent the experience of the employees through digitalization. They have created a new digital human resource management team along with information technology for security and infrastructure purpose. They created an application called Embard through which the employees know more about their work, know about the organization culture, and the employees can meet the team through an online platform. RBC has planned for 
developing an application for Compelling Careers through a digital platform and also to develop a digital system for career development, learning and job transaction.

\section{View on Digital Hr from the Perspective of Other Countries}

1. Digitalization takes places in Human Resource management since the traditional HR pushed themselves to be part of this digital world.

2. $56 \%$ of companies worldwide have restructured their human resource program to bring digital technology and mobile phones.

3. $51 \%$ of company's worldwide have implemented digital technology in the organization.

4. From the survey report it showed that almost $33 \%$ of organization are using AI to deliver better Human Resource Solution, and $40 \%$ of them have developed mobile application to deliver significant human resource solution for business organization.

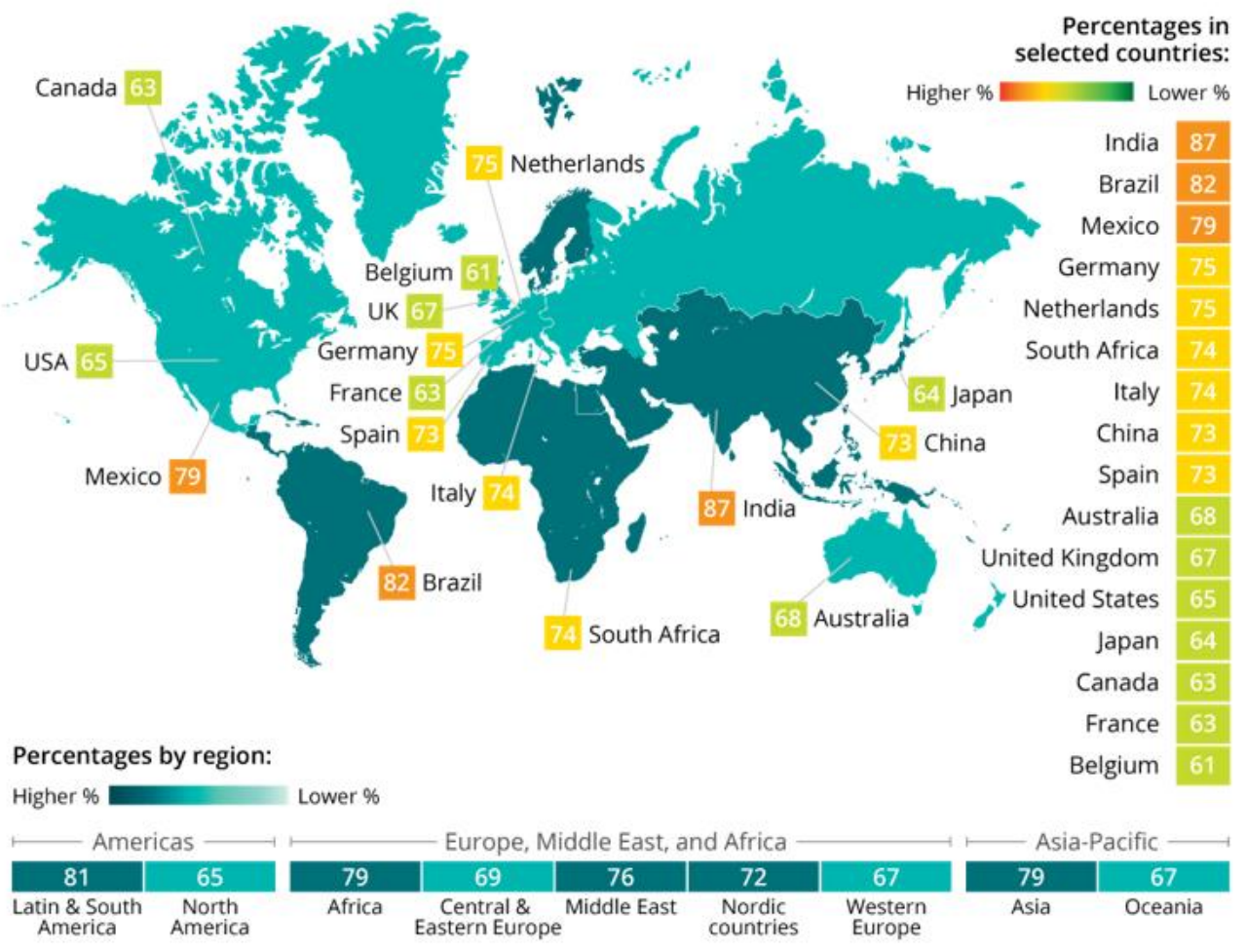

Figure 5: Digital HR practice worldwide and its percentage of utilization

The human Resource Department has undergone a massive evolution in the past 5 years. Especially in the past 3 years many companies are implementing or collaborating with cloud-based systems in the HR platform. The human Resource department necessarily needs a new revolution on the whole structure, by restructuring the field with skilled HR professionals, implementing analytics, etc. but in the present scenario, digital management practice has gained more importance among organizations. Now the present Human Resource management has changed to a digital form which tries to focus on people, organization, employees, and work, etc. now the resulting human Resource Practice will be termed as Digital Human Resource. Digital HR was developed based on the effort made for several years.

In the 1960s ad $1970 \mathrm{HR}$ mainly focused on automating transactions, maintaining an efficient system, personal operation, etc.

In the 1980s HR focused on a service organization by completely redesigning it and it was considered as the core practice for business success, and it was the time where HR was completely implemented in organization for business motive.

In the 1990s and 2000s, HR was restructured again with the motive of integrating it with talent management which can be done along with the implementing of a new process for employee recruitment, performance management, compensation, and learning.

In the present situation, HR mainly focuses on making this field be the best department in the aspect of business organization. They want an integrated, digital experience at work-one designed around teams, productivity, and empowerment - and HR is expected to deliver it. 


\section{Conclusion}

Digital Human Resource Management is considered as the basic need in the aspect of business organization. Every business organization has a long way to go by adopting digitalization. Digital HRM helps in maintaining a strong relationship between management and its employees. By preparing a strategy for DHRM will help in organizational performance. This study tries to highlight the importance of DHRM in the aspect of the organization and by enhancing the recruitment process by creating an application by the top leading organization. The outcome of the research paper will act as an important aspect for researchers to implement further research on DHRM.

Every organization should develop its digital strategy to improve productivity. In the present scenario, DHRM is considered a more significant and growing research topic as well as an important topic for a business organization. With the use of DHR practice and through social media, the internet, AI, and other technology organization can maintain their performance and employees' quality standard for the smooth running of the organization.

\section{References}

- Kontić, Ljiljana, and Đorđe Vidicki. "Strategy for digital organization: Testing a measurement tool for digital transformation." Strategic Management 23.1 (2018): 29-35. Crossref

- $\quad$ Spitzer, Barbara. "HR in the digital age." Workforce Solutions Review 5.1 (2014): 15-17.

- Goldstein, J. "Digital technology demand is transforming HR." Workforce Solutions Review 6.1 (2015): 28-29.

- Deloitte Consulting, L. L. P., and J. Bersin. "Global human capital trends 2016: the new organization: different by design." (2016).

- Cöster, Mathias, et al. "Conceptualising innovative price models: the RITE framework." Baltic Journal of Management (2019). Crossref

- Makridakis, Spyros. "The forthcoming Artificial Intelligence (AI) revolution: Its impact on society and firms." Futures 90 (2017): 46-60. Crossref

- Shah, Naimatullah, Zahir Irani, and Amir M. Sharif. "Big data in an HR context: Exploring organizational change readiness, employee attitudes and behaviors." Journal of Business Research 70 (2017): 366-378. Crossref

- Ebersold, Kyle, and Richard Glass. "The Impact of Disruptive Technology: The Internet of Things." Issues in Information Systems 16.4 (2015).

- Halid, Hafinas, Yusmani Mohd Yusoff, and Hemalatha Somu. "The Relationship Between Digital Human Resource Management and Organizational Performance." First ASEAN Business, Environment, and Technology Symposium (ABEATS 2019). Atlantis Press, 2020. Crossref

- Larkin, James. "HR digital disruption: the biggest wave of transformation in decades." Strategic HR review (2017). Crossref

- Huselid, Mark A. "The impact of human resource management practices on turnover, productivity, and corporate financial performance." Academy of management journal 38.3 (1995): 635-672. Crossref

- Bredin, Karin, and Jonas Söderlund. Human resource management in project-based organizations: The HR quadriad framework. Springer, 2011. Crossref

- Leopold, John, and Lynette Harris, eds. The strategic managing of human resources. Pearson Education, 2009.

- Kavanagh, Michael J., Mohan Thite, and Richard D. Johnson. "The Future of HRIS." Emerging Trends in HRM and IT (2009).

- Maditheti, Nishad Nawaz. "A Comprehensive Literature Review of the Digital HR Research Filed." organization 7.4 (2017).

- Saini S. Digital HRM and its Effective Implementation: An Empirical Study, International Journal of Management Studies, 2(7), 2018. Crossref

- Iwu, C. G. Effects of the use of electronic human resource management (E-HRM) within human resource management (HRM) functions at universities. Acta Universitatis Danubius, Administration, 8(1), 2016.

- Betchoo, N. K. Digital transformation and its impact on human resource management: A case analysis of two unrelated businesses in the Mauritian public service. In 2016 IEEE International Conference on 
Emerging Technologies and Innovative Business Practices for the Transformation of Societies (EmergiTech) (pp. 147-152). IEEE, 2016. Crossref

- $\quad$ Tripathi, R., \& Kushwaha, P. A study on Innovative Practices in Digital Human Resource Management. National Seminar on Digital Transformation of Business in India: Opportunities and Challenges. Dehradun: IMS Unison University, 2017.

- Fedorova, A., Zarubina, A., Pikulina, Y., Moskovskikh, A., Balandina, T., \& Gafurova, T. Digitalization of The Human Resource Management: Russian Companies Case. International Conference on Education, Social Sciences and Humanities, 12271230, 2019.

- Banu, S. R. HR Digital Transformation. Journal of the Gujarat Research Society, 21(13), 946-951, 2019.

- Nawaz, N., \& Gomes, A. M. Human resource information system: A review of previous studies. Journal of Management Research, 9(3), 2017. Crossref

- $\quad$ Aggarwal, V. \& Sharon S. D. Digital Human Resource Management. 11 (2), Gyan Management, 2017.

- DiRomualdo, A., El-Khoury, D., \& Girimonte, F. HR in the digital age: how digital technology will change HR's organization structure, processes and roles. Strategic HR Review, 2018. Crossref

- Bondarouk, T. V., \& Ruël, H. J. Electronic Human Resource Management: challenges in the digital era. The International Journal of Human Resource Management, 20(3), 505-514, 2009. Crossref

- Kiesler, Sara, Jane Siegel, and Timothy W. McGuire. "Social psychological aspects of computer-mediated communication." American psychologist 39.10 (1984): 1123. Crossref

- Heracleous, Loizos. Strategy and organization: Realizing strategic management. Cambridge University Press, 2003. Crossref

- Yusoff, Yusmani Mohd, et al. "Linking green human resource management practices to environmental performance in hotel industry." Global Business Review 21.3 (2020): 663-680. Crossref

- Mosca, Maria. Digitalization of HRM: a study of success factors and consequences in the last decade. MS thesis. University of Twenty, 2020. 